\title{
The Canadian Association of Gastroenterology Strategic Plan: Where are we in 2014?
}

\author{
Derek McKay President, David Armstrong President Elect, Dan Sadowski Past President, \\ Sandra Daniels Manager CAG National Office, Paul Sinclair Executive Director
}

\begin{abstract}
A Strategic Plan for the Canadian Association of Gastroenterology (CAG) was first established in 1993 and a new plan was set again in 2004. The most recent strategic plan for the period of 2010-2015 has been published (1), and we take this opportunity to update you on the initiatives completed or underway toward the goals set in 2010.

GOAL: CAG will enhance support for our research community's traditional strengths in biomedical and clinical research, while broadening its scope to the other CIHR pillars, including quality assurance, by maintaining current and developing new funding partnerships to sustain and enhance research funding through studentships, fellowships, operating grants, and career support awards
\end{abstract}

- Together with the CIHR and partners, the CAG annually offers research funding to all levels of training, including grants to clinicians and new investigators, postdoctoral fellows, gastroenterology residents, and summer students. The impressive output from this program from 2000-2008 was recently published (2). This amounted to more than $\$ 17.4$ million in funding to support 131 fellowship awards, seven career transition awards, and 22 operating grants. Comparative analyses indicate that publications supported by the funding program had a greater impact than other Canadian and international comparators.

- The CAG Visiting Research Professorship and recently launched CAG Visiting Clinical Professorship provide the opportunity for sites across Canada to benefit from the research and clinical expertise of the high profile CAG members awarded these positions each year. Each Visiting Professor annually visits six to nine centres across Canada.

- Since 2001, the annual Research Topics in Gastrointestinal Disease Meeting has provided graduate students, $\mathrm{PhD}$ and $\mathrm{MD}$ postdoctoral trainees with an intimate setting in which to present their research findings, engage in career development workshops, and skill building exercises with enthusiastic experts in the field.

- The CAG supplies grants to support organizers of workshops and has recently launched a conference grant competition.

- The Association applies for relevant grants, as they become available, to promote digestive health, such as to the Canadian Partnership Against Cancer to support the CAG's quality endoscopy programs and CIHR Meeting Planning and Development grants in aid of clinical practice guideline development and dissemination.

GOAL: CAG will continue to develop and evaluate initiatives that improve access to, and the quality of, digestive health care delivery for all Canadians, by:

Identifying, recruiting and fostering the next generation of digestive health providers including practitioners, basic scientists, clinician scientists, educators, managers, advocates and leaders
Educating members about quality assessment, providing innovative tools, and developing, disseminating and monitoring the adoption of standards and guidelines

Improving access to quality care by engagement and education of the public and health policy makers through the CDHF and other means

- The many research funding opportunities noted above support the next generation of scientists.

- The CAG offers a wide variety of educational events and tools including the Canadian Digestive Diseases Week conference, the Gastroenterology Residents-in-Training Course, the Scholars' Program to entice internal medicine residents to specialize in gastroenterology, the educational Portal (ePortal) website for members, the CAG Expert Seminar Series, and online continuing medical education.

- Introduced in 2012/2013, the CAG's Skills Enhancement for Endoscopy $\odot$ (SEEC) addresses gaps in the quality of endoscopy skills by offering Train-the-Colonoscopy-Trainer courses and Master Classes in Colonoscopy.

- The CAG sends the annual Young Educator Awardee to the World Gastroenterology Organization's Train-the-Trainer program which brings together up-and-coming educators from various countries to provide them with an opportunity to hone their skills.

- Since 2012, the CAG has been offering its volunteers the opportunity to attend the CAG fall forum to take part in key development workshops such as the negotiation workshop facilitated by Dr Janice Stein in 2013.

- Another recent initiative launched is the CAG Fellow (CAGF), a professional designation recognizing longstanding members who have made significant contributions to the Association.

- As above, the CAG Visiting Research Professor and Visiting Clinical Professor lecture to institutions and gastroenterology groups across Canada.

- The Quality Program - Endoscopy, available to any endoscopy unit in Canada, allows units to monitor and improve the quality of the patient-centred endoscopy services they deliver.

- The CAG produces a wealth of clinical practice guidelines to support clinicians. Recently published guidelines include venous thrombosis in inflammatory bowel disease, quality and safety indicators in endoscopy, severe ulcerative colitis (inpatients) and nonvariceal upper gastrointestinal bleeding. Guidelines being developed address Helicobacter pylori, dysphagia, dyspepsia, mild to severe ulcerative colitis (outpatients), capsule endoscopy, IBD and pregnancy, and screening for colon cancer in patients at high risk.

- The CAG has issued position statements to guide clinicians on contentious issues such as subsequent entry biologics in inflammatory bowel disease, hip fracture and proton pump inhibitor therapy, and the use of thiopurines.

The CAG is proud to acknowledge its Benefactor Corporate Sponsors:
AbbVie Corporation
Actavis Specialty Pharmaceuticals Co
Olympus Canada Inc

Pentax Canada Inc

Janssen Inc

Takeda Canada Inc 
- The Association engages health policy makers through its partnership and liaises with the Canadian Partnership Against Cancer, the National Colon Cancer Screening Network, the Wait Time Alliance, as well as the Canadian Medical Association and Royal College of Physicians and Surgeons of Canada (RCPSC).

- The CAG continues to promote the visibility of the CDHF through events at CDDW and communiqués to the membership. The CAG has assisted the CDHF in remodeling their governance structure and meeting the new Industry Canada continuance requirements.

GOAL: CAG will expand communication as a core competency that is supported by expertise, tailored to a diverse digestive health services constituency, and delivered via multiple media by:

Developing a formal communication strategy that adheres to the following guiding principle: "All messages, whether they are core or customized, should be harmonious and aligned to the goals and aspirations of CAG"

Emphasizing face-to-face interactions and dialogue between CAG members and the digestive health community

Expanding the degree of dialogue with partners and other organizations in order to amplify the services we provide to members

- The CAG engaged a communications company to develop a communications plan whose facets continue to be implemented and expanded as below.

- Introduction of quarterly email communications to update the CAG volunteers and our partners on decisions and directions of the Association.

- Introduced 'President's Communiques' as a periodic information piece in the monthly electronic newsletter to members.

- The CAG alerts members to forthcoming media releases and provides them with a chance to review final draft clinical practice guidelines before submission for publication.

- Created uniform branded information sheets, about the CAG and its activities, for use with members and stakeholders.

- The Canadian Digestive Diseases Week app was introduced in 2013, and provides delegates with comprehensive information on the conference, venue and area information.

- Plans are underway for a media call list of gastroenterologists who have taken media training.

- Membership videos to showcase CAG activities are being developed.

- $\mathrm{CAG}$ is developing memorandums of understanding with key health care partners including Crohn's and Colitis Canada, Canadian Institutes of Health Research and the Canadian Association for the Study of the Liver.

GOAL: CAG will focus on attracting new members while engaging, retaining, and adding value for the existing membership of gastroenterologists, digestive health researchers, and the digestive health constituency by ascertaining and addressing the needs of the digestive health services constituency.

- The CAG offers members numerous benefits through its four categories of membership.

- See above for the research, education and quality programs, clinical practice guidelines and CAGF designation which benefit members and non-members.

- The CAG provides an annual bursary to a Canadian Society of Gastroenterology Nurses and Associates member to support the individual's attendance at Canadian Digestive Diseases Week.

- The CAG Board has implemented a plan to attend, on an annual basis, provincial/regional gastroenterology society meetings, holding focus groups with their members, and looking for ways to enhance the partnerships.
CAG will be the preeminent accredited provider for continuing education for our members and other digestive health providers by:

Identifying gaps in learner knowledge and skills, both perceived and unperceived, and anticipating emerging educational needs

Becoming a key provider of knowledge transfer through the effective and appropriate delivery of programs

Advancing a regional outreach strategy linking with regional groups and provincial associations to support a range of activities

- The CAG has been awarded the RCPSC Innovation award in 2011 (for the CAG Practice Audit web-based platform) and 2012 (for the CAG ePortal).

- The ePortal is a web space dedicated to helping the membership keep up to date and fulfill their education/Maintenance of Certification requirements.

- Practice audits in areas such as inflammatory bowel disease and irritable bowel syndrome allow physicians to earn credits while examining practice patterns.

- The CAG evaluates perceived needs via the annual educational needs assessment survey that is used to develop educational events. The CAG works with other national specialty societies to uncover unperceived educational needs.

- The residents' webinar series provides gastroenterology residents the opportunity to attend a number of webinar lectures throughout the academic year on a variety of topics from the field of gastroenterology.

- The CAG introduced a new education research grant aimed to foster quality research in medical education, as well as maintain, and grow this important role within Canadian gastroenterology.

- The Skills Enhancement for Endoscopy@ program and Visiting Clinical and Research Professorships noted above also assist with educational needs.

- To support provincial associations, the CAG produces and maintains annually a national fee database and offers accreditation/ co-development of regional programs. The CAG Visiting Professors have been utilized extensively within provincial/regional society meetings.

CAG will prepare for the future needs and opportunities in digestive health care by:

Exploration of areas such as the role of diet and nutrition, microbiology, oncology in digestive health care

Establishing a future trends digestive health care task force whose mandate will include development of a health promotion and disease prevention strategy

- A nutrition committee was formed under Education Affairs and more nutritional segments have been incorporated into Canadian Digestive Diseases Week.

- Past President's meetings are held to utilize experience and wisdom of CAG leadership to develop strategies as above.

- A task force, to address human resource related issues (job availability, training needs, changes in delivery of care), has been formed.

\section{REFERENCES}

1. Bridges RJ, Morgan D, Sinclair P, Sadowski D. Looking forward: The Canadian Association of Gastroenterology strategic plan. Can J Gastroenterol 2011;25(4):183-5.

2. Sherman PM, Banks Hart K, Rose K et al. Evaluation of funding gastroenterology research in Canada illustrates the beneficial role of partnerships. Can J Gastroenterol 2013;27(12):717-20. 


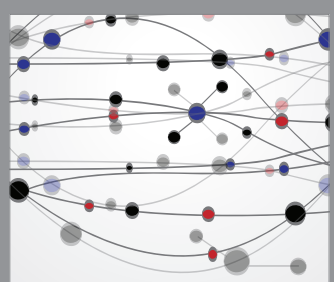

The Scientific World Journal
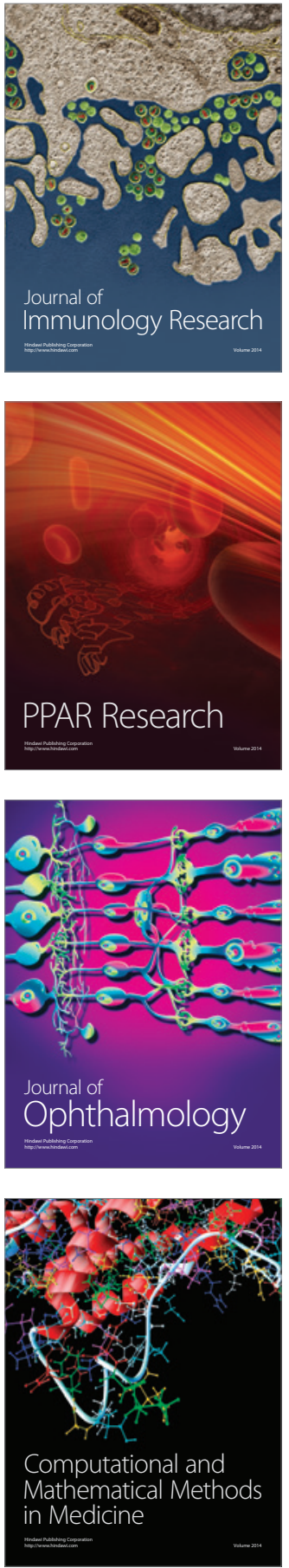

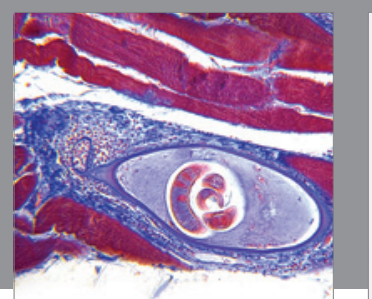

Gastroenterology Research and Practice

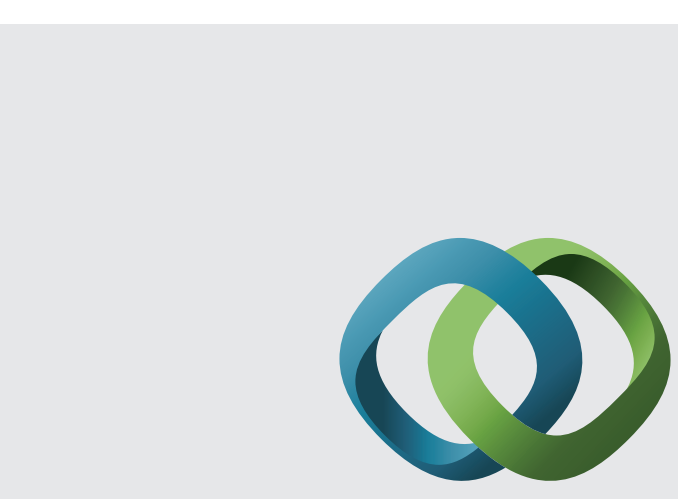

\section{Hindawi}

Submit your manuscripts at

http://www.hindawi.com
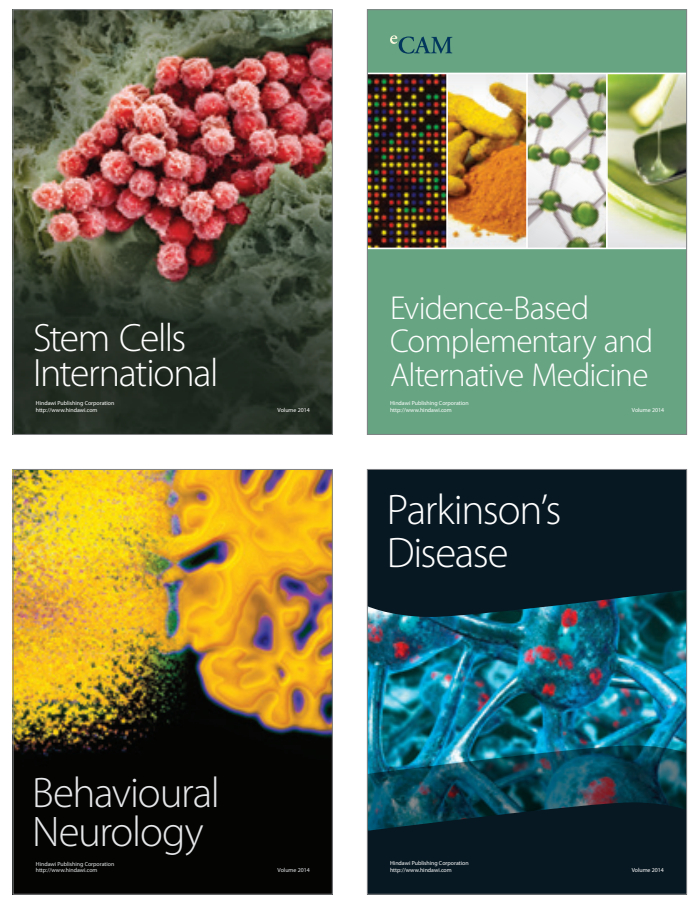
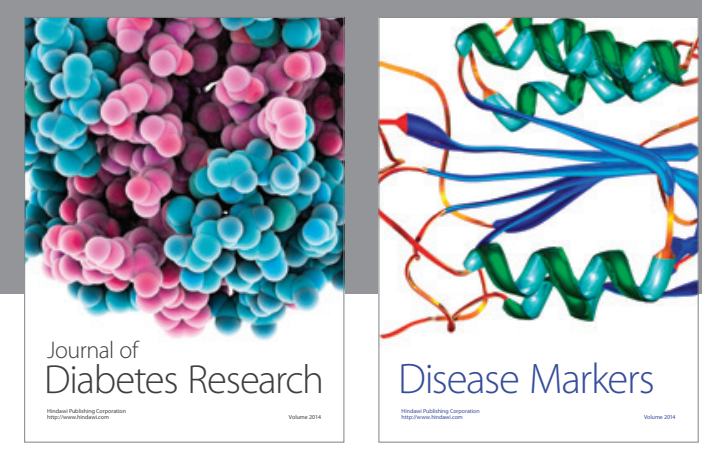

Disease Markers
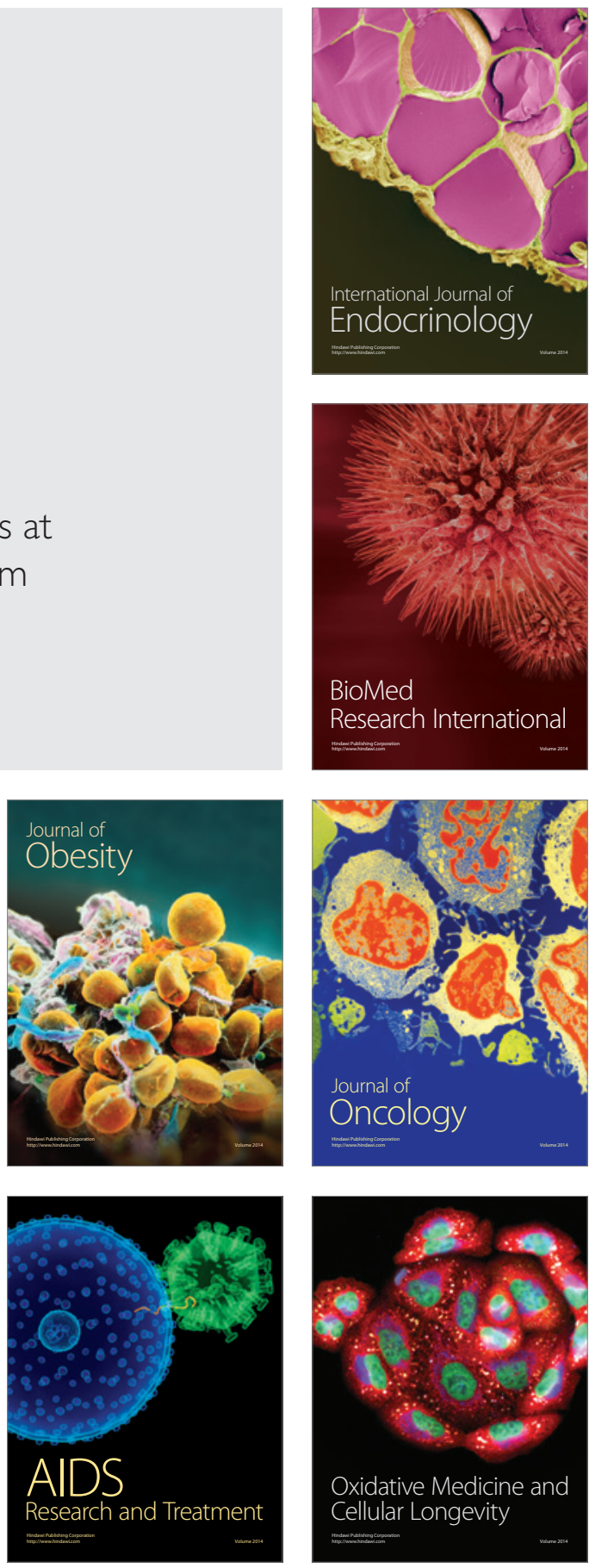